\title{
Memory transfer in planarians: An artifact of the experimental variables
}

\author{
D. R. WALKER \\ UNIVERSITY OF VICTORIA ${ }^{1}$
}

The conditioning rate of naive planarians which had ingested light-shock conditioned worms was compared with that of control groups which had ingested shock-exposed, light-exposed, and light-shock extinguished Ss, as well as with an original conditioning group. None of the cannibals showed systematic increase in conditioned responses over 75 trials, and there was no difference in the number of conditioned responses emitted by the conditioned-cannibal group. This is interpreted as supporting an hypothes is that tissuesensitivity to the experimental variables rather than memory transfer had occurred.

Humphries \& Jacobsen (1961) have shown that the ingestion of conditioned planaria has a marked positive effect on the response level of naive planaria. McConnell (1962) interpreted the data as indicating that memory transfer by cannibalism had been demonstrated and it was tentatively hypothesized that the vehicle of this transfer was coded ribonucleic acid (RNA).

Although the original studies included Cannibal Control (CC) Groups, which had ingested naive worms, they did not include a Cannibal Shock Control (CSC) Group, which had ingested shocked-only worms, nor a Cannibal Light Control (CLC) Group, which had ingested worms receiving photic stimuli only.

Hartry, Keith-Lee \& Morton (1964) included CLC and CSC groups in their design and found that both groups performed better than the CC Group, in fact the performance of the CLC Group was superior to that of the Experimental Cannibals (XC), who had ingested conditioned worms. Walker \& Milton (1966) found a positive relationship between the amount of shock received by the cannibalized worms and the number of conditioned responses of the cannibals. They interpreted this result as well as the findings of Hartry et al (1964) and original conditioning data of Crawford, Livingston, \& King (1966) as support for a sensitization hypothesis. Jensen (1965) suggests doubt that planarians are ever really conditioned.

The interpretive differences between Walker \& Milton (1966) and McConnell (1962) hinge on whether it is some form of sensitization to the experimental variables which is transferred or whether it is memory (association between the experimental variables).

The present study further explores the hypothesis that the cannibalism effect is due to sensitivity to the experimental variables, by comparing the effects of ingestion of conditioned worms with the effects of ingestion of extinguished worms. While the response to light might still be in the repertoire of the extin- guished $\mathrm{S}$, the dominant response (presumably coded in RNA) at the time of ingestion would be the response of ignoring or not responding to the light. Accordingly, the memory transfer hypothesis would have to predict that the performance of the cannibals of conditioned and extinguished worms (Group EC) would, at best, be equal to that of naive worms, while the sensitization hypothesis would predict that the performance of the CE group would be equal to that of the XC Group. CLC and CSC groups were also run.

Method

The apparatus, subject population and conditioning procedure were those used by Walker \& Milton (1966). Eight groups of six Ss each were run. Four groups were cannibalized and four groups were cannibals. The experimental treatments for the cannibalized Ss were as follows. The Ss in Groups $\mathrm{E}$ and $\mathrm{X}$ were matched as closely as possible for the number of trials to a criterion of $13 \mathrm{CRs}$ in 15 consecutive trials. Twenty-four hr. after Ss in Group E had reached criterion they were administered 25 extinction trials and $24 \mathrm{hr}$. later an additional 25 extinction trials were given. On completion of the extinction trials Group E was killed by dehydration and fed immediately to Group EC.On attaining criterion the Ss in Group X were placed in their home aquariums and $48 \mathrm{hr}$. later were killed and fed immediately to Ss in Group XC. All conditioning was carried out in blocks of 25 trials per day. Group $L$ received $3 \mathrm{sec}$. exposures to light and Group S received 1 sec.exposures to shock. Groups $L$ and $S$ received 25 trials per day. The Ss in Groups $L$ and $S$ were matched for exposures to stimuli with Ss in Groups X. Forty-eight hr. after their last trial Ss in Groups $L$ and S were killed and fed to cannibals in Groups CLC and CSC respectively. Groups $\mathrm{XC}, \mathrm{EC}, \mathrm{CSC}, \mathrm{CLC}$ were administered 25 conditioning trials per day for three days. All Ss were coded and run blind by the two $\mathrm{Es}^{2}$ between whom an interscorer reliability check was made.

\section{Results and Discussion}

Interscorer agreement on conditioned responses was 94\%. Extinction of the CR in Group $\mathrm{E}$ was rapid and no $S$ made more than three responses in the last 10 trials.

The principal data consists of the number of CRs made by the cannibal groups in the 75 conditioning trials. The mean number of responses per block of 25 trials for these groups as well as the mean number of responses for the $\mathrm{X}$ group is presented in Table 1 .

Analysis of variance of this data indicates that there are significant effects due to the experimental conditions $(\mathrm{F}=3.01, \mathrm{df}=4 / 25, \mathrm{p}<.05)$ and due to an interaction 
Table 1. Mean number of CRs per block of 25 trials.

\begin{tabular}{lrrr} 
& \multicolumn{3}{c}{ Trial Blocks } \\
Treatments & $1-25$ & $26-50$ & $51-75$ \\
\hline$X$ & 8.40 & 9.60 & 11.20 \\
XC & 15.83 & 11.30 & 11.64 \\
EC & 13.83 & 13.00 & 12.16 \\
CLC & 10.30 & 8.00 & 10.50 \\
CSC & 8.50 & 9.60 & 10.16 \\
\hline
\end{tabular}

between experimental conditions and blocks of trials $(\mathrm{F}=2.66, \mathrm{df}=8 / 50, \mathrm{p}<.05)$. This interaction is particularly interesting, for it reflects the finding that Group $\mathrm{X}$ (the original worms) was the only group of Ss to show significant "conditioning" effects $(F=5.63$, df $=$ $2 / 10, p<.05)$. The CSC group did not show signs of significant change in CRs over the 75 trials $(F=.26$, $\mathrm{df}=2 / 10$ ) nor did the CLC or EC groups. The XC group, in fact, showed a systematic decrease in CRs over the 75 trials $(F=7.99, \mathrm{df}=2 / 10, \mathrm{p}<.05)$, which suggests the operation of an adaptation phenomenon similar to that found for turning responses by Crawford et al (1966). Such an adaptation could be consistent with sensitization, but not with a transfer of conditioning or memory hypothesis.

Comparison of the XC and EC groups provides no evidence of differential savings. The two groups behaved quite similarly with regard to the total number of CRs emitted ( $F=.00, \mathrm{df}=1 / 10)$, but the EC group did not show as steep a decline in the number of CRs over blocks of trials $(F=3.46, \mathrm{df}=2 / 20, \mathrm{p}<.05)$. Regardless of how the "memory" was coded, whether it be in RNA or some as yet unknown factor, the memory transfer hypothesis would predict that performance of Group EC would be poorer than that of Group XC. The sensitization hypothesis is, however, adequate to handle the results. Although sensitization to cues is involved in conditioning, sensitization, as used in this paper, refers to a non-associative physiological process, such as the lowering of receptor thresholds.

\section{References}

Crawford, F. T., Livingston, Patsy A., \& King, F. J. Distribution of practice in the classical conditioning of planarians. Psychon. Sci., 1966, 4, 29-30.

Hartry, A. L., Keith-Lee, P., \& Morton, W. D. Planaria: memory transfer through cannibalism re-examined. Science, 1964, 146 , 274-275.

Humphries, B., \& Jacobson, R. The effects of ingestion of conditioned planaria on the response level of naive planaria: II, Worm Runner's Digest, 1961, 3, 165-169.

Jensen, D. D. Paramecia, planaria, and pseudo-learning. Animal Behaviour Supplement $l, 1965,9-20$.

McConnell, J. V. Memory transfer through cannibalism in planaria. J. Neuro-Psychiat., 1962, 3, 45.

Walker, D. R., \& Milton, G. A. Memory transfer vs. sensitization in cannibal planarians. Psychon. Sci., 1966, 5, 293-294.

\section{Notes}

1. Now at the University of Iowa.

2. Patricia Walker participated as E, and G. A. Milton consulted on the design and manuscript. 